\title{
Study of Factors Related to and Limitations in Facilities Provided to Near Miss Pregnancies Attending Obstetrics Department in Our Institution
}

\author{
${ }^{1}$ Third Year Resident, Department of Obst \& Gynecology \\ ${ }^{2}$ Assistant Professor, Department of Obst \& Gynecology \\ ${ }^{3}$ Associate Professor, Department of Obst \& Gynecology \\ ${ }^{4}$ Assistant Professor, Department of Obst \& Gynecology
}

Dr. Krupali B. Jasani ${ }^{1}$, Dr. Nilam Prajapati ${ }^{2}$, Dr. Anjani Shrivastava ${ }^{3}$, Dr. Kedar Trivedi ${ }^{4}$

\begin{abstract}
Objectives: To study factors related to near miss pregnancies in our setting. To study limitations in facilities provided to near miss pregnancies in our setting. Materials and Methods: This observational study was carried out in department of Obstetrics and Gynaecology, in our institute, enrolling 100 consecutive subjects with near miss admitted to labour room and obstetrics intensive care unit of our institute, over a period of around 1 year from December 2014-June 2015. As per the WHO criteria, all pregnant women with high risk condition were selected; all their details entered in standard proforma, effective interventions were recorded. Conclusion: Maximum cases of maternal near miss were found in subjects with age group of 20-30 years, who were illiterate, below poverty line, with gestational age of 22-34 weeks without any prior ANC visits with multi organ disorder mainly haematological. Results: Out of 100 near miss pregnancies majority of them had hematological disorder, who were survived with effective intervention (appropriate and adequate transfusion of blood products and ICU monitoring
\end{abstract}

\section{Introduction}

Maternal Near Miss: A woman who survived life threatening conditions during pregnancy, abortion and child birth or within 42 days of pregnancy termination irrespective of receiving emergency medical/surgical intervention is called Maternal Near Miss.

Maternal mortality is a critical indicator to assess the quality of services provided by a health care system. The standard indicator for measuring it is the Maternal Mortality Ratio (MMR), defined as the ratio of the number of maternal deaths per 100,000 live births. Globally there has been decline in MMR, in India too this is declining steadily due to the additional efforts and resources put under NHM for improving health care. There is a need to further accelerate this decline for achieving our national and international goals and targets under them. It is well known that complications during pregnancy and child birth can occur at any point of time, and it is important to ensure that readiness in terms of infrastructure, HR, equipment etc. for timely management of complications are available at all the basic and emergency obstetric care health facilities. If such complications are not managed on time they can become fatal. The Maternal Death Review guidelines launched by Government of India is a tool available with health managers and policy makers at various levels to critically look at health system performance, identify gaps and initiate corrective steps through convergent action.

\section{Objectives}

To study factors related to near miss pregnancies in our setting. To study limitations in facilities provided to near miss pregnancies in our setting.

\section{Materials and Methods}

This observational study was carried out in department of Obstetrics and Gynaecology, in our institute, enrolling 100 consecutive subjects with near miss admitted to labour room and obstetrics intensive care unit of our institute, over a period of around 1 year from December 2014-June 2015.

\section{Inclusion Criteria}

All pregnant women who fulfill WHO criteria for near miss. All patients with critical condition during pregnancy and within 24 hours of postpartum registered in our Antenatal clinic at our institute, it includes.

1) Cardiovascular dysfunction

2) Respiratory dysfunction.

3) Renal dysfunction.

4) Coagulation haematological dysfunction.

5) Hepatic dysfunction.

6) Neurological dysfunction.

7) Uterine dysfunction

\section{Exclusion Criteria}

All pregnant women attending NCHS without following dysfunction.

1) Cardiovascular dysfunction.

2) Respiratory dysfunction.

3) Renal dysfunction.

4) Coagulation haematological dysfunction.

5) Hepatic dysfunction.

6) Neurological dysfunction.

7) Uterine dysfunction

- Case identification as per the criteria. (all pregnant women with high risk condition attending OBGYN department of NCHS during one year period)

- All the details collected of patients (Biodata, chief complaints, $\mathrm{O} / \mathrm{H}, \mathrm{P} / \mathrm{H}, \mathrm{F} / \mathrm{H}$, general examination, 


\section{International Journal of Science and Research (IJSR) \\ ISSN (Online): 2319-7064}

Index Copernicus Value (2015): 78.96 | Impact Factor (2015): 6.391

systemic examination, intervention, factors that not provided to patients)

- All the details of the patients collected in a proforma

- The intervention that saved the mother is recorded

Advantages of investigating near miss events;

- Near miss cases are more common than maternal deaths

- The major reasons and causes are the same for both MNM and MDR, so review of MNM cases is likely to yield valuable information regarding severe morbidity, which could lead to death of the mother, if not intervened properly and in time.

- Investigating the instances of severe morbidity may be less threatening to providers because the woman survived.

- One can learn from the women themselves since they survived and are available for interview about the care they received.

- All near misses should be interpreted as free lessons and opportunities to improve the quality of service provision.

\section{Indicators for Monitoring ${ }^{1}$}

1) Total Number of MNM cases in the reporting month

2) MNM cases reviewed by $\mathrm{CMHO}$

3) Out of total MNM cases indicate the number against following complication:
a) $\mathrm{PPH}$
b) Eclampsia
c) Anemia
d) Septic Abortion
e) others

4) Type of gaps identified after review

5) Status of corrective action taken for the gaps identified

\section{Observation and Discussion}

Table 1: Age
\begin{tabular}{|l|c|l|}
\hline AGE & N=100 & Percentage \\
\hline$<20$ years & 01 & $1 \%$ \\
\hline $20-30$ years & 94 & $94 \%$ \\
\hline$>30$ years & 05 & $5 \%$ \\
\hline
\end{tabular}

Majority of subjects in present study i.e. $94 \%$ were between 20-30 years. Those below 20 years out of 100 subjects were $1 \%$ (reflecting the lower age of the mother at the time of the first conception in our population)

Table 2: Education

\begin{tabular}{|l|l|l|}
\hline Illiterate & 61 & $61 \%$ \\
\hline Literate up to 5th Class & 36 & $36 \%$ \\
\hline 6th-12th Class & 03 & $03 \%$ \\
\hline$>12$ th Class & 00 & $0 \%$ \\
\hline
\end{tabular}

Majority of the subjects $(61 \%)$ were illiterate. Out of 100 subjects, 3 subjects are educated between $6^{\text {th }}-12^{\text {th }}$ class, 36 subjects were literate up to $5^{\text {th }}$ class. No one out of these subjects was literate beyond $12^{\text {th }}$ class.
Table 3: Parity

\begin{tabular}{|c|c|c|}
\hline 0 & 32 & $32 \%$ \\
\hline $1-2$ & 54 & $54 \%$ \\
\hline $2-3$ & 10 & $10 \%$ \\
\hline$>3$ & 04 & $04 \%$ \\
\hline
\end{tabular}

We analysed the distribution of our subjects with respect to their parity. Majority of the subjects $54 \%$ were in the range of 1-2 parous state. Out of 100 subjects, $32 \%$ were nulliparous, $10 \%$ were ranging between $2-3$ and $4 \%$ were showing $>3$ parity.

Table 4: Type of Admission

\begin{tabular}{|l|c|c|}
\hline Self & 57 & $57 \%$ \\
\hline Referral & 43 & $43 \%$ \\
\hline
\end{tabular}

Out of 100 subjects, $57 \%$ subjects were self-admitted while $43 \%$ were referred to our institute.

Table 5 (Socioeconomic Status)

\begin{tabular}{|l|c|c|}
\hline BPL & 71 & $71 \%$ \\
\hline NOTBPL & 29 & $29 \%$ \\
\hline
\end{tabular}

Out of 100 subjects, $71 \%$ are below poverty line and $29 \%$ are not below poverty line.

Table 6 (Underlying Disorder during Admission)

\begin{tabular}{|l|c|c|}
\hline 1. Heamorrhage & 20 & $20 \%$ \\
\hline 2. Infection & 15 & $15 \%$ \\
\hline 3. Hypertensive Disorder & 30 & $30 \%$ \\
\hline 4. Labour Related Disorder & 03 & $03 \%$ \\
\hline 5. Medical Disorder & 62 & $62 \%$ \\
\hline 6. Incidental/ Accidental Cause & 00 & $00 \%$ \\
\hline
\end{tabular}

We analysed the distribution of our subjects with respect to their condition which represented their underlying disorders at time of admission.

Majority of the subjects out of 100 subjects had a medical disorder (Non Obstetric causes) that was about $62 \%$.

In that, subjects with anaemia were of $67.74 \%$.

$6.45 \%$ subjects had been suffering from heart disease and $4.84 \%$ subjects had been suffering from lower respiratory tract infection.

None of them had diabetes.

In our study, $30 \%$ of subjects were having hypertensive disorders of pregnancy.

Amongst this, $53.33 \%$ were having eclampsia, $36.67 \%$ were having pre-eclampsia, $6.67 \%$ were having gestational hypertension and $3.83 \%$ had other conditions.

In our study, $20 \%$ of subjects were having haemorrhagic conditions.

Out of this, $40 \%$ were having placental abruption, $40 \%$ were having postpartum bleeding, $15 \%$ were having placenta praevia, $5 \%$ were having abortion history. 


\section{International Journal of Science and Research (IJSR) \\ ISSN (Online): 2319-7064 \\ Index Copernicus Value (2015): 78.96 | Impact Factor (2015): 6.391}

There was no incidence of Ectopic pregnancy, Gestational Trophoblastic Disorder, Late pregnancy, bleeding disorders other than placental causes and intrapartum bleeding in the study.

In our study, $15 \%$ of subjects were having infective etiology.

Out of this, $46.67 \%$ had postpartum causes, $20 \%$ were having antepartum causes, $20 \%$ were having intrapartum causes while $13.33 \%$ had post-abortal causes.

In our study, $3 \%$ of subjects were having labour related disorders.

Out of this, $66.67 \%$ were having retained placenta and $33.33 \%$ were having prolonged/obstructed/rupture uterus.

There was no incidence of inversion of uterus and others.

Comparison of near miss pregnancies between present study and Rulisa et al study 2012(Africa) in relation to the underlying condition at time of admission as under.

So the subjects with haemorrhage and hypertensive disorder of pregnancy in both the studies were comparable.

So majority of the subjects in our studies were anaemic while subjects with sepsis were comparable with adeoye et al study 2007 (Nigeria)

This shows that in present study majority of the subjects were with haematological disorder.

Table 7: Antenatal Period (ANC visit)

\begin{tabular}{|c|c|c|}
\hline Yes & 46 & 46 \\
\hline If Yes type of care provider & & \\
\hline Nurse & 05 & $10.87 \%$ \\
\hline Medical Officer & 23 & $50 \%$ \\
\hline Specialist & 17 & $36.95 \%$ \\
\hline Others including privet sector & 01 & $2.17 \%$ \\
\hline No & 34 & $54 \%$ \\
\hline
\end{tabular}

We analysed the distribution of our subjects with respect to their antenatal period details.

In this study, 54\% subjects did not receive any ANC visits.

$46 \%$ subjects received ANC visits- out of which, 50\% received it from medical officer, $36.95 \%$ received it from specialists, $10.87 \%$ received it from nurses while there were $2.17 \%$ subjects who received it from others.

\section{Discussion}

Majority of the subjects who reached with severe illness did not receive the ANC visits which were essential for prevention and early diagnosis of pregnancy related disease and complications.
Table 8: Positive Clinical Findings

\begin{tabular}{|l|l|l|}
\hline General & 89 & $89 \%$ \\
\hline CNS & 29 & $29 \%$ \\
\hline CVS & 63 & $63 \%$ \\
\hline RS & 08 & $08 \%$ \\
\hline Abdominal Findings & 35 & $35 \%$ \\
\hline Hematological & 72 & $72 \%$ \\
\hline GUT & 24 & $24 \%$ \\
\hline Immune & 01 & $01 \%$ \\
\hline
\end{tabular}

We analysed the distribution of our subjects with respect to their clinical findings.

Majority of the subjects that is $89 \%$ had positive general findings.

$72 \%$ had positive haematological findings, $63 \%$ had positive cardiovascular findings, $35 \%$ had positive abdominal findings, $29 \%$ had positive central nervous system findings, $24 \%$ had positive genitourinary findings, $8 \%$ had positive respiratory findings and 15 had involvement of the immune system.

Majority of the subjects had disorders related to haematological system

Table 9: Interventions

\begin{tabular}{|l|l|l|}
\hline ICU Admission & 60 & $60 \%$ \\
\hline Blood Products Transfusion & 62 & $62 \%$ \\
\hline MgSO4/Mannitol & 27 & $27 \%$ \\
\hline Resuscitation & 01 & $1 \%$ \\
\hline Others & 12 & \\
\hline Internal iliac ligation & 02 & \\
\hline Mechanical ventilation & 07 & \\
\hline Central line insertion & 02 & \\
\hline Pleural Tapping & 12 & 01 \\
\hline
\end{tabular}

So majority of the patients received ICU care and transfusion of blood products in present study.

Comparison with various studies

\begin{tabular}{|c|c|c|c|}
\hline Name of Study & Criteria & $\begin{array}{l}\text { Study } \\
\text { Result }\end{array}$ & $\begin{array}{l}\text { Present Study } \\
\text { Result }(\mathrm{n}=100)\end{array}$ \\
\hline $\begin{array}{c}\text { De saude et al } \\
(\mathrm{n}=255)\end{array}$ & $\begin{array}{l}\text { Maternal near } \\
\text { miss ratio }\end{array}$ & 56 & 39 \\
\hline Rulisa el al $(n=192)$ & Age (20-30 yrs) & $77.6 \%$ & $94 \%$ \\
\hline $\begin{array}{l}\text { De saude et al } \\
\quad(n=255)\end{array}$ & Education & $43.2 \%$ & $3 \%$ \\
\hline Rulisa et al $(n=192)$ & $\begin{array}{c}\text { Socio- } \\
\text { economic status }\end{array}$ & $77.6 \%$ & $71 \%$ \\
\hline Adeove et al $(n=75)$ & Referral & $47 \%$ & $43 \%$ \\
\hline Kalra et al $(n=112)$ & Parity & $48.2 \%$ & $54 \%$ \\
\hline Kalra et al $(n=112)$ & Gestational age & $53.5 \%$ & $33 \%$ \\
\hline Rulisa et al $(n=192)$ & Hypertension & $28.6 \%$ & $30 \%$ \\
\hline Rulisa et al $(n=192)$ & Haemorrhage & $30 \%$ & $20 \%$ \\
\hline Adeove et al $(n=75)$ & Anaemia & $14.6 \%$ & $42 \%$ \\
\hline Adeove et al $(n=75)$ & Sepsis & $14 \%$ & $15 \%$ \\
\hline $\begin{array}{c}\text { De saude et al } \\
(\mathrm{n}=255)\end{array}$ & $\begin{array}{c}\text { Hematological } \\
\text { disorder }\end{array}$ & $4 \%$ & $72 \%$ \\
\hline $\begin{array}{c}\text { JP souza et al } \\
(n>=200)\end{array}$ & ICU admission & $15.8 \%$ & $60 \%$ \\
\hline $\begin{array}{c}\text { De saude et al } \\
(\mathrm{n}=255)\end{array}$ & $\begin{array}{l}\text { Blood products } \\
\text { transfusion }\end{array}$ & $65.1 \%$ & $62 \%$ \\
\hline Zanette et al & Mechanical & $2.83 \%$ & $7 \%$ \\
\hline
\end{tabular}

Volume 6 Issue 7, July 2017 www.ijsr.net

Licensed Under Creative Commons Attribution CC BY 


\section{International Journal of Science and Research (IJSR) \\ ISSN (Online): 2319-7064}

Index Copernicus Value (2015): 78.96 | Impact Factor (2015): 6.391

\section{Conclusion}

Maximum cases of maternal near miss were found in subjects with age group of 20-30 years, who were illiterate, below poverty line, with gestational age of 22-34 weeks without any prior ANC visits with multi organ disorder mainly haematological. Early diagnosis and critical care under ICU and adequate transfusion of appropriate blood products helped in the survival of majority of our near miss pregnancies thereafter preventing their maternal mortality in our setting.

So it is important to improve health care services to create awareness of healthcare providers and patients regarding early warning signs of high risk pregnancies and maternal near miss and thereby intervene at appropriate time in near miss pregnancies to prevent maternal mortality.

\section{References}

[1] Maternal Near Miss Review Operational Guideline

[2] World Health Organization, UNICEF, UNFPA and The World Bank. Trends in maternal mortality: 1990 to 2008. Geneva: World Health Organization, 2010

[3] Campbell OM, Graham WJ, Lancet Maternal Survival Series Steering Group. Strategies for reducing maternal mortality: getting on with what works. The Lancet, 2006,368:1284-1299.

[4] Freedman LP et al. Practical lessons from global safe motherhood initiatives: time for a new focus on implementation. The Lancet, 2007, 370:1383- 1391.

[5] Pattinson RC, Hall M. Near misses: a useful adjunct to maternal death enquiries. British Medical Bulletin, 2003, 67:231-243.

[6] Say L et al. WHO systematic review of maternal morbidity and mortality: the prevalence of severe acute maternal morbidity (near miss). Reproductive Health, 2004, 1(1):3 (DOI:10.1186/1742-4755-1-3).

[7] Cecatti JG, et al. Research on severe maternal morbidities and near-misses in Brazil: what we have learned. Reproductive Health Matters, 2007, 15:125-133.

[8] Say L et al., WHO working group on Maternal Mortality and Morbidity Classifications. Maternal near misstowards a standard tool for monitoring quality of maternal health care. Best Practice \& Research Clinical Obstetrics \& Gynaecology, 2009,23:287-296.

[9] Pattinson R et al. WHO maternal death and nearmiss classifications. Bulletin of the World Health Organization, 2009, 87:734-734A.

[10] Graham WJ. Criterion-based clinical audit in obstetrics: bridging the quality gap? Best Practice \& Research Clinical Obstetrics \& Gynaecology, 2009, 23(3):375-388.

[11] Introducing WHO's sexual and reproductive health guidelines and tools into national programmes: principles and process of adaptation and implementation. Geneva, World Health Organization, 2007.

[12] Report on the World Health Organization Working Group on the Classification of Maternal Deaths and Severe Maternal Morbidities. Geneva, World Health Organization, 2009.

[13] International statistical classification of diseases and related health problems. Tenth revision, Volume 2. Geneva, World Health Organization, 1993.
[14] WHO recommendations for the prevention of postpartum haemorrhage. Geneva, World Health Organization, 2007.

[15] WHO Guidelines for the management of postpartum haemorrhage and retained placenta. Geneva, World Health Organization, 2009.

[16] Duley L et al. Magnesium sulfate and other anticonvulsants for women with preeclampsia. Cochrane Database of Systematic Reviews, 2007; Issue 4. Art. No.: CD000025 (DOI: 10.1002/14651858.CD000025).

[17] Smaill F, Hofmeyr GJ. Antibiotic prophylaxis for cesarean section. Cochrane Database of Systematic Reviews, 2007; Issue 4. Art. No.: CD000933 (DOI: 10.1002/14651858.CD000933).

[18] Dellinger RP et al.; International Surviving Sepsis Campaign Guidelines Committee; American Association of Critical-Care Nurses; American College of Chest Physicians; American College of Emergency Physicians; Canadian Critical Care Society; European Society of Clinical Microbiology and Infectious Diseases; European Society of Intensive Care Medicine; European Respiratory Society; International Sepsis Forum; Japanese Association for Acute Medicine; Japanese Society of Intensive Care Medicine; Society of Critical Care Medicine; Society of Hospital Medicine; Surgical Infection Society; World Federation of Societies of Intensive and Critical Care Medicine. Surviving Sepsis Campaign: international guidelines for management of severe sepsis and septic shock: 2008. Critical Care Medicine, 2008, 36:296-327.

[19] Roberts D, Dalziel S. Antenatal corticosteroids for accelerating fetal lung maturation for women at risk of preterm birth. Cochrane Database of Systematic Reviews, 2007, Issue 4. Art. No.: CD004454 (DOI: 10.1002/14651858.CD004454. pub2).

[20] Lauritsen JM, Ed. EpiData data entry, data management and basic statistical analysis system. Odense, Denmark, EpiData Association, 2000- 2008 (available at: http://www.epidata.dk).

[21] Epi-Info. Atlanta, GA, Centers for Diseases Control and Prevention (available at: http:// wwwn.cdc.gov/epiinfo).

[22] Souza JP et al. The World Health Organization Multicountry Survey on Maternal and Newborn Health: study methods. BMC Health Services Research, 2011.

[23] Cecatti JG et al.; Brazilian Network for Surveillance of Severe Maternal Morbidity. Brazilian network for the surveillance of maternal potentially life threatening morbidity and maternal near miss and a multidimensional evaluation of their long-term consequences. Reproductive Health, 2009, 6:15.

[24] Althabe F et al. Guidelines Trial Group. A behavioral intervention to improve obstetrical care. New England Journal of Medicine, 2008, 358:1929- 1940.

[25] Rogers, E.M. Diffusion of innovations. Fifth edition. New York, Free Press, 2003. 